\title{
LA POÉTICA DEL TIEMPO: UNA APROXIMACIÓN AL IMAGINARIO STEAMPUNK
}

\author{
PABLO PRIETO HAMES \\ Universidad Pompeu Fabra. Barcelona
}

\begin{abstract}
Resumen
El presente trabajo constituye una reflexión sobre cómo el fenómeno artístico y las técnicas de creación han cambiado de forma radical a lo largo de la segunda mitad del s. XX, centrándose en la relación hombre-tecnología. Esta propuesta nos conducirá desde los orígenes de la Revolución Industrial de la "Inglaterra Victoriana" hasta la actualidad. Nos centraremos en cómo se pasa de un concepto de progreso por el avance tecnocientífico al rechazo del mismo a través de las contraculturas y los retrofuturismos, profundizando en todos los imaginarios que de ellos se desprenden. Mediante futuros que nunca existieron y pasados que pudieron haber sido, el retrofuturismo otorgará al artista una gran oportunidad para reflexionar sobre sí mismo, dejándose llevar por su lado más crítico hacia el capitalismo y el "Do It Yourself".
\end{abstract}

\section{Palabras clave}

Retrofuturismo, steampunk, época victoriana, arte actual

\author{
TIME POETICS: AN APPROACH TO AESTHETIC IMAGINARY \\ STEAMPUNK
}

Abstract

This work is presented as a reflection on how the artistic phenomenon and building techniques have dramatically changed over the second half of the 20th Century, essentially focusing on the human- technology relationship. This proposal will lead us from the very origins of the Victorian England's Industrial Revolution to nowadays. We will also focus on how it is moved from a concept of progress purely conceived through techno-scientific to the advanced rejection of itself through counterculture and retrofuturism, diving into all the imaginary ones which emerged from it. By a future that never existed and past times that may have been but never ocurred, the retrofuturism give the artist such a great opportunity to reflect upon himself, carried away by his own and most critical side towards capitalism and the "Do It Yourself" movement.

\section{Key words}

Retrofuturism, steampunk, Victorian era, contemporary art

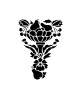

Ucoarte. Revista de Teoría e Historia del Arte, 5, 2016, pp.95-115. ISSN: 2255-1905 


\section{La génesis del imaginario colectivo}

La retrospección es, quizás, la actividad más recurrente en el ser humano: añoramos cualquier tiempo pasado que fue mejor, más sugestivo o sencillamente más interesante. Llegados al momento clave de nuestra fascinación, en algunas ocasiones, hasta nos habremos preguntado ¿Qué hubiera pasado sí...? Y de repente, nos convertimos inconscientemente en creadores de una nueva "realidad" compuesta por acontecimientos y situaciones que nunca hubieron ocurrido. Esta característica es la que hace del retrofuturismo ${ }^{1}$, más concretamente de su subgénero, el steampunk algo ecléctico e interesante.

Por lo tanto, el steampunk se caracteriza por la nostalgia y la melancolía de un pasado inexistente, un pasado reinventado que configura un tiempo con influencias futuras, abrazando la ciencia y la tecnología como medios que hacen posible formular un imaginario repleto de influencias artísticas, las cuales convergerán en torno a un núcleo movido por la maquinaria a vapor. Así, destacaremos el empleo de engranajes, turbinas, tuberías, hierros, aspas, chimeneas, relojes, medidores o termómetros, zeppelines, globos aerostáticos y un largo etcétera de artilugios, como elementos de composición y de inspiración de la estética retrofuturista.

Todos los elementos citados tienen algo en común, son los exponentes más paradigmáticos de la época victoriana. El concepto "steam" (vapor) vendría a servir de nexo de unión entre el reinado victoriano y la actualidad, apelando directamente, mediante el símbolo de la maquina a vapor, a todos los avances tecnológicos y sociales que se produjeron durante el reinado victoriano. El gobierno de la Reina Victoria se extendió durante sesenta y cuatro años, constituyendo el más largo de Gran Bretaña. Durante su reinado se originarán los primeros avances tecnocientíficos de los que podemos gozar aún en la actualidad. Se inventa el ferrocarril, hecho revolucionario que cambió por completo la visión del ciudadano respecto al mundo, así como su concepción de la distancia. Aparecieron el gramófono, la máquina de escribir, el teléfono, el neumático de goma, los pantalones vaqueros, y un largo etcétera de elementos novedosos. Además, en el ámbito científico Hertz generó las primeras ondas de radio, Edison inventó la bombilla eléctrica y Marley puso de manifiesto la inexistencia del éter. Por su parte, Charles Darwin con su teoría de la evolución, sentó las bases del mundo moderno y cambió por completo la justificación de la existencia del ser humano. Todo ello tuvo como consecuencia que el hombre del siglo XIX depositara una fe ciega en la ciencia. La sociedad de la época creyó que los científicos -casi como si se tratara de dioses- podrían conseguir hasta lo imposible, pues la ciencia era vista como una herramienta capaz de modificar las leyes naturales para imponer los deseos de la sociedad; una opinión que cambiaría posteriormente con la formulación de la teoría de la relatividad de Einstein.

Las fábricas, las construcciones en hierro, el vapor y finalmente la máquina, se convertirán así en "musas" de los artistas, propiciando en el ámbito literario la creación del género de la ciencia ficción. Así, por ejemplo, se escriben Los viajes extraordinarios de Julio Verne y las primeras obras de H.G. Wells, que abrían los caminos de la fascinación y especulación científica a la sociedad. Hoy en día sabemos que esas tecnologías, al igual que las producidas actualmente, fueron y son víctimas del carácter de obsolescencia predominante desde finales del siglo XIX, produciendo así más avances que las sustituyeron e imposibilitando su

${ }^{1}$ El retrofuturismo propone la creación artística mediante idas y venidas entre pasado y futuro; verdaderos viajes en el tiempo de la creación que se actualizan, a través de diferentes registros, en nuestro presente evolutivo. El artista y editor americano Lloyd Dunn fue el primero que supo apreciarlo a comienzos del año 1980, principalmente en los ámbitos de las artes gráficas, el diseño y la arquitectura. El retrofuturismo apoya su base creativa en las visiones del futuro anteriores a los años sesentas. Así, podemos resumir el proceso creativo como un juego de pasado y futuro, en el que intervienen los anacronismos y las disrupciones a través de una estética del pasado nostálgico y la naturaleza anticipativa de aquello que está representado; el resultado es una escena vintage del futuro que juega con la ilusión de un pasado en el cual el futuro, hipotético y retro, habría hecho irrupción más temprano de lo previsto. 
desarrollo más amplio y la construcción de un futuro a su imagen y semejanza ${ }^{2}$. Pero ¿Y si no hubiese sido así? $?^{3}$ El steampunk nace, mediante esta fórmula, de una fuerte tensión entre pasado, presente y futuro. Y resulta llamativo que, cada vez con más frecuencia, se asome a nuestra cultura de masas, redibujando así sectores enteros de la imaginería popular y apelando a un sentimiento de ucronía, para alterar el pasado y cambiar el futuro posibilitando concebir robots u ovnis bajo una apariencia propia de los años treinta a los sesenta. La ucronía ${ }^{4}$ posibilita que bajo la perspectiva del steampunk que todo se pueda realizar con metales remachados, engranajes, madera y la energía motriz del vapor, resaltando el valor más retro de todo cuanto nos rodea ${ }^{5}$.

\section{Movimiento steampunk. Origen e influencias.}

El movimiento steampunk, al igual que su coetáneo el Cyberpunk, se originará en las dos últimas décadas del siglo XX. Los escritores Tim Powers, K.W. Jeter y James Blaylock, serán quienes asienten el imaginario steampunk que, posteriormente, fructificará en un gran movimiento con múltiples propuestas artísticas. Estos autores se reunían en el bar O'Hara's en Orange (California), y será allí donde se conformen todas las premisas esenciales de la subcultura. El extraño término de steampunk surge por azar, cuando Tim Powers escribe una carta al editor que publicaba las primeras novelas steampunk del trío literario y donde le contaba que K.W. Jeter era el inventor de esa palabra como alusión irónica al cyberpunk ${ }^{6}$. Sin embargo, en un primer momento podemos considerar uno de los fundadores del movimiento a Michael Moorcock, creando historias en las que, aunque sus dirigibles no siempre iban propulsados a vapor, se presentaban conflictos políticos y militares, se rechazaba la idea de un imperio benigno y se presentaba la innovación tecnológica como instrumento de represión y control de los gobiernos. Estos autores tomarán como punto de partida y elementos de inspiración a los escritores de la época victoriana como H.G. Wells y Julio Verne, quienes serán los autores más recurrentes, aunque también se producen referencias a las obras de Lewis Carroll, Charles Dickens o Lord Byron, aunque no se sitúen dentro del marco contextual victoriano.

El origen del steampunk se produce, por tanto, en el seno de la literatura con la imaginación desplegada en los relatos de autores como Julio Verne o H.G. Wells, mediante el desarrollo del género literario de "Les Contes Philosophiques". Esos relatos serán muy importantes pues, tomando como base las obras de Francis Bacon, se desarrollará en ellos el viaje imaginario y el cuento onírico como medio para explicar viajes imposibles a través del sistema solar o hacia las profundidades de la tierra. Ahora bien, esto tenía un punto débil: la credibilidad. Un viaje al espacio resultaba imposible si al final todo era fruto del sueño de un protagonista que acababa despertando. El personaje protagonista debe ser plenamente consciente, responsable y participativo de las acciones dramáticas, por lo que autores como Julio Verne o H.G. Wells profundizan en el grado de "realidad" necesario para hacer posible un mundo que, por entonces, se creía fantástico.

En el caso de Julio Verne, su obra La casa de Vapor (1880) y otras como Veinte mil leguas de viaje submarino (1869) propagarán una serie de inventos pioneros que cristalizarán en nuestros

\footnotetext{
2 Palma et alii, 2012: 9-12.

${ }^{3}$ Como señaló el periodista americano Douglas Fetherling, a propósito del steampunk, "imaginar hasta qué punto el pasado hubiera podido ser diferente si el futuro hubiera llegado más temprano" es otra de las premisas del steampunk. En relación con las palabras de Fetherling, véase Morvan, Sylvain (2015): "Les rétrofuturistes du steampunk, cette science-fiction du passé". En http://www.wedemain.fr/Les-retrofuturistes-dusteampunk-cette-science-fiction-du-passe_a907.html [16/06/16].

${ }^{4} \mathrm{El}$ termino ucronía fue acuñado por el filósofo Charles Renouvier en su ensayo Uchronie, l'utopie dans l'histoire (1876). La palabra hace referencia a un no-tiempo y remite a una temporalidad paralela, alternativa, generada por una reescritura de la historia a base de omisiones, modificaciones e invenciones pasadas.

${ }^{5}$ Sanz et alii, 2012: 4-6.

${ }^{6}$ Barilier/Colson, 2014: 58.
} 
días, haciéndolo a través de un lenguaje donde la temática a vapor será la protagonista. Mientras que las obras de Verne se centrarán en los adelantos científicos de su época, H.G. Wells se ocupará más de la descripción de su sociedad y la diferenciación de clases enfatizando en la media-baja-, al tiempo que mostrará su inclinación por la defensa de los derechos de la mujer. Sin embargo, añadirá elementos fantásticos a sus obras como, un hombre que es invisible, en su novela El hombre invisible (1897), la presencia de seres del espacio en La guerra de los mundos (1898), o una máquina para viajar en el tiempo en La máquina del tiempo (1895). La diferencia radica en que Julio Verne se recreaba con más detalle en las aplicaciones y estéticas de las nuevas tecnológicas o incluso en inventar nuevos usos de las mismas a través de hechos comprobados, valiéndose de métodos y materiales que no se apartaban completamente del mundo de la ingeniería ni del conocimiento de la época. Mientras que, por el contrario, H.G. Wells no se obsesionaba tanto por la minuciosidad descriptiva, ni por la verosimilitud, sino que dejaba al lector un espacio mayor para la interpretación. Sus historias eran fantasía y sus máquinas eran tratadas con un carácter más decorativista que funcional, produciéndose en el ámbito literario -al igual que hoy en día lo hacen los artistas steampunk- la frontera entre artista y artesano. Además, Wells formulará un futuro que será imposible, pero imbuido por el mundo científico y por la realidad social en la que vive compuesta por diferencias de clases, conflictos entre capital y trabajo, el colonialismo, imperialismo o el racismo.

Por lo tanto, la temática del "progreso" se convierte en eje central de producción del steampunk, así como la mezcla de lo artificial y mecánico con lo natural. En este sentido, nos sirve como ejemplo el Nautilus de Veinte mil leguas de viaje submarino de Verne, que combina la forma de buque con la de una ballena ${ }^{7}$. Así, veremos cómo en este movimiento cobrarán gran importancia los cachivaches de Julio Verne al tiempo que, por influencia de Wells, se abordarán cuestiones sociales como el ecologismo o el anarquismo. Además, se crearán tanto mundos de terror como de belleza, con el fin de vislumbrar una pesadilla tecnológica fruto de la fascinación por la innovación científica y por su aplicación en las diferentes guerras.

No debemos olvidar, por otra parte, que el imaginario steampunk que encontramos hoy en día también recibe influencia de EEUU y sus dime novels, cuyos temas en esencia eran el Western y la posibilidad de ascensión de la pobreza a la fortuna. En ellas, se nos presentaba a un joven inventor escapando de un entorno con ciertos toques nacionalistas, lo cual resultaba desfavorable, y que utilizaba como medio de transporte un vehículo a vapor. Aportan así la fórmula del "todo es posible", configurando un mundo donde la máquina de cada genio superará al anterior y donde hay posibilidad de rebelarse contra el sistema para mejorar la condición social. Es decir, se propone una alternativa artística que va más allá del placer estético.

De hecho, el Steampunk tiene tanta aceptación porque, a pesar de que utilice la estética y tecnología de la época victoriana, reconoce dentro de esa época cuestiones y problemas parecidos a los que se enfrenta la sociedad en el siglo XXI. Ante esto, el artista steampunk tendrá una doble elección, bien dedicarse a cuestiones similares desde el contexto actual, o bien tomar de Verne y Wells sus escenarios victorianos y las fascinaciones hacia inventos extraños y científicos locos. Independientemente de la posición adoptada, obtendrán una esencia cargada tanto de la nostalgia creativa de Verne como de una dosis crítica. Incluso, en ciertos momentos, se acercará al futuro de pesadilla de Wells, encontrando a la vez un vínculo entre la inocencia creativa y lo distópico.

Volviendo a los años ochenta y partiendo de todas estas características creativas llenas de viajes temporales, inventos extraños y científicos locos, Tim Powers escribirá Las puertas de Anubis, la cual recoge todos los ingredientes que incorporarán las novelas o relatos steampunks, de ahora en adelante. En la obra se produce la combinación del viaje en el tiempo propio de Wells, con una historia de antiguos dioses y del dominio británico en

\footnotetext{
7 También estará influenciado por la estética de los acorazados, que empezaron a desarrollarse en la Guerra de Secesión Americana (1861-1865).
} 
Egipto tras la derrota de Napoleón por parte de Horatio Nelson en la Batalla del Nilo. También, aparecerán personajes reconocidos, ya sean reales ${ }^{8}$ o ficticios, dentro de un contexto en el que los británicos suprimirán el culto a los antiguos dioses egipcios, lo que provoca la ira de una cábala de hechiceros que planearán una trama para expulsar al ejercito inglés y acabar con el Imperio Británico, trayendo del pasado a los dioses ancestrales para liberarlos en Londres. El relato comienza en 1802, sucediendo algo durante la invocación de Anubis que repercutirá en la actualidad, pues se abrirán portales predecibles para viajar en el tiempo y éstos serán aprovechados por un millonario que realizará expediciones al pasado. El protagonista, Brendan Doyle, será contratado por éste para realizar una de esas expediciones y quedará atrapado en el s. XIX. En general, a la novela se le otorgará un enfoque social, haciendo hincapié en las tecnologías mecánicas o el vapor, se jugará con el espacio-tiempo y, finalmente, con la verosimilitud a través la utilización de hechos históricos y personajes que realmente existieron.

Otro aspecto interesante del steampunk fue su combinación con el ciberpunk, como se pudo apreciar en la obra paradigmática de William Gibson y Bruce Sterling, La máquina diferencial ${ }^{9}$, adquiriendo la denominación de Ciberpunk histórico. Alcanzará una gran fama dentro del género, pues será la primera en la que se enfatice la concepción más distópica del movimiento, a través de una historia desarrollada en 1855. En ella Charles Babbage construyó con éxito una computadora mecánica permitiendo, en esta época temprana, el desarrollo de la información al mismo tiempo que la Revolución Industrial. También, aparecerá un Partido Radical Industrial liderado por Lord Byron y compuesto por revolucionarios contrarios a la tecnología predominante, hecho por el cual serán perseguidos. El imperio británico se configurará como la superpotencia, promoviendo la investigación y otorgando títulos nobiliarios a científicos como Charles Darwin. Habrá dirigibles con motor de reacción, alimentados a base de carbonilla, combinados con inteligencia artificial mecánica alojada en la fachada de una pirámide egipcia en Londres. En general, también se apreciarán dentro del ámbito literario influencias de las novelas Pulp y, lo más importante, todos ponen de manifiesto en sus novelas la cuestión esencial que se planteará el movimiento "Qué hubiera pasado si..."

El steampunk cuenta con una vertiente crítica como podemos observar en el cómic Puppet Makers. Una creación fruto de los ilustradores Molly Crabapplem y John Leavitt, quienes para el sello Zuda de $D C$ comics, se recrean en el libertinaje histórico, pero altamente sexualizado a través de elementos como burlesque, prostitutas y cortesanas. Sirviéndose de un Versalles alternativo con claros elementos steampunk combinados con ciborgs mecánicos que critican cómo la vida de la mujer cortesana, entre pelucas, corsés y protocolos, hubiera sido mejor llevada por robots en lugar de seres humanos. Por otra parte, Alan Moore y Kevin O’Neill crearon otro comic steampunk que, también, tuvo acogida en la gran pantalla, La Liga de los Hombres Extraordinarios (2003) donde se regresa a la época victoriana mediante personajes icónicos como el Capitán Nemo, el Hombre Invisible o el doctor Jekyll, entre otros. Se mezclan así los escritores de Penny Dreadful con Verne y Wells, parodiándose los elementos victorianos a la vez que se interesan por reunir a los personajes icónicos de los mundos de la ficción ${ }^{10}$.

Además, el steampunk no sólo se difundirá por la literatura, sino que también la moda servirá como puente hacia la creación de la cultura steampunk. De hecho, será la vía más recurrente para acceder a un mayor número de adeptos. Se trata de una característica muy

\footnotetext{
${ }^{8}$ Poetas románticos como Lord Byron o S. T. Coleridge.

9 La máquina diferencial y la maquina analítica estarán muy presentes en el imaginario steampunk, especialmente por su estética. Junto a su creador Charles Babbage, considerado "padre de la computación” y creador del primer instrumento para calcular con el fin de no cometer errores en las tablas matemáticas, la máquina diferencial, y en las tablas de navegación, la maquina analítica (aunque ésta no fuera terminada). Su objetivo era simple, evitar la mayoría de los errores posibles, el elemento humano. Ada Byron, la hija de Lord Byron ayudó a Babbage escribiendo el considerado como primer lenguaje de programación de la historia.

${ }^{10}$ Vandermeer/Chambers, 2011: 80-84.
} 


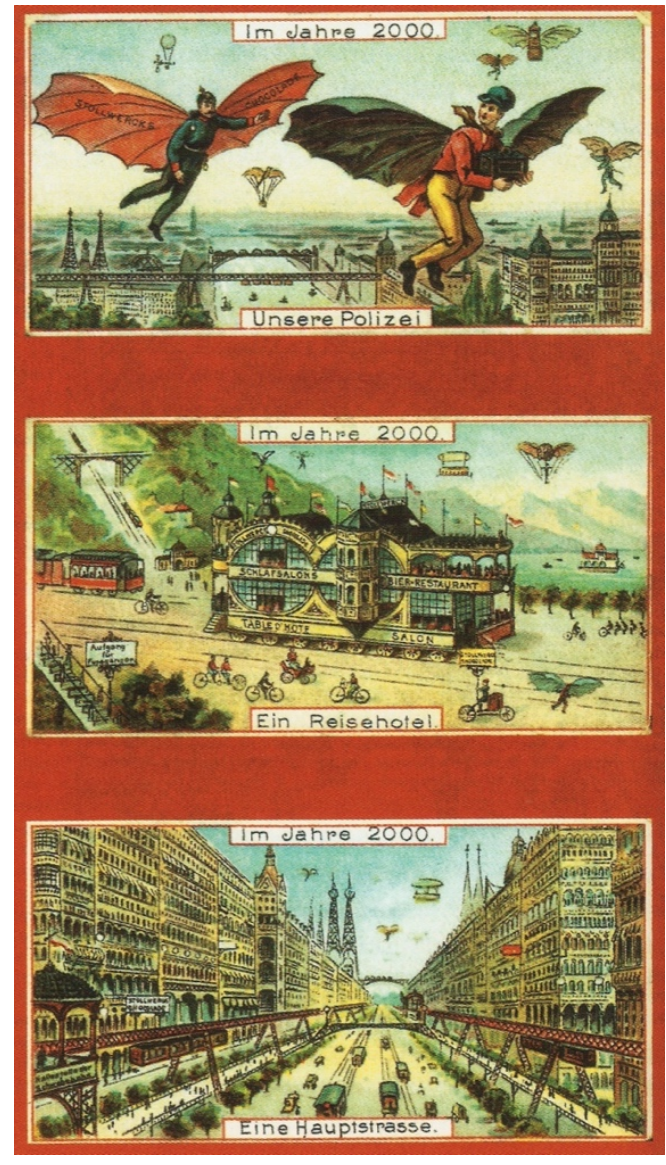

Fig. 1. Tarjetas de imágenes publicitarias realizadas en $1897-98$ por la Fábrica de chocolate Gebr Stollwerck

interesante -aunque no podamos extendernos en profundidad-, pues será entendida como una steam imagen. Así, la ropa dice algo de ti y responde a la imagen que uno mismo se ha creado, ante lo cual su temática irá acompañada de una narración de las experiencias vividas, como también, se pueden encontrar personas que sigan la moda por mero placer formal.

Dentro de esta conformación de la steam imagen, las únicas leyes generales que se pueden apreciar son: la reacción en contra de las restricciones que imponía la sociedad victoriana y el "Do It Yourself", estando así muy presente el reaprovechamiento de material para dotarlo de una nueva perspectiva y funcionalidad, es decir, deconstruir para reinventar.

La sensación que produce la ropa steampunk es cronológicamente ecléctica. Por ello, ya no sólo nos retrotraeremos a la época victoriana anglosajona, sino que el toque punk se hará cada vez más latente, conduciendo el estilo hacia una rebeldía que no duda en utilizar las culturas primitivas de reservas americanas, el salvaje oeste americano o la tradición oriental. Además, se refuerza el multiculturalismo, la imaginativa propia en contra del fenómeno de globalización actual y la producción en serie.

El aspecto más punk ("hazlo tú mismo") existente en la moda y en la artesanía conduce también a una reflexión sobre el mundo que habitamos. Un mundo contaminado por las diferentes industrias de energías nocivas como las petroleras o las nucleares. Por ello, actualmente el steampunk se centra en investigar sobre un producto sostenible para favorecer un modo de vida ecológico en el que se produzcan tecnologías en armonía con la naturaleza. De esta manera, la nostalgia del steampunk no sólo consistirá en recrear un tiempo pasado donde una tecnología empleada actualmente no fuera dañina, sino también en la capacidad de reparar uno mismo su reloj o su coche, como hicieran en el pasado nuestros antecesores. Modificando la forma en la que interactuamos con la tecnología, acompañada de un sentido más rebelde de la vida en la revolución "hazlo tú mismo". Cómo diría Margaret Killjoy, 
Fig. 2. Maison tournante aérienne para su libro Le Vingtième Siècle.

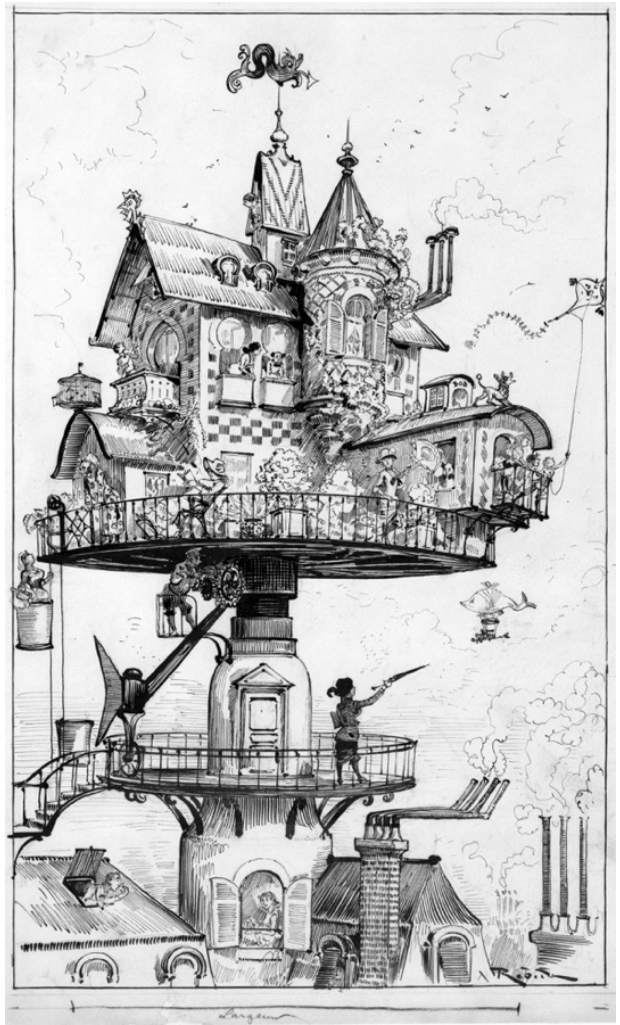

cofundadora de la revista paradigmática Steampunk Magaz̨ine: "Podemos ofrecer personas con un enfoque sostenible en relación con la tecnología y la manera de vivir. Podemos ayudar a la gente a darse cuenta de que el progreso no es necesariamente lineal. Podríamos ir hacia atrás para poder seguir adelante"11.

Por otro lado, la nostalgia conduce a lugares que ya no corresponden con el espíritu de la Inglaterra Victoriana sino, más bien, con una visión del steampunk multicultural gracias a la aparición de Internet y la globalización, elementos que hacen del movimiento un fenómeno catalizador de culturas, al tiempo que acrecienta los diferentes enfoques que puede utilizar el artista en sus obras, pues en realidad todo es fruto de una puesta en común. Hablaríamos así de una nueva perspectiva gremial 2.0, en la que el creador no tiene que viajar por diferentes escuelas para aprender las diferentes propuestas artísticas, sino que a través de Internet puede ampliar su bagaje con tan solo un clic de su ordenador ${ }^{12}$.

\section{Estética atemporal: entre la prospección y la retrospección.}

Como hemos visto, el origen del steampunk es eminentemente literario y estrechamente relacionado con el modelo de sociedad tecnocientífica que se inicia a partir de la industrialización victoriana. Los artistas steampunk estarán influenciados por todas esas especulaciones y visiones procedentes de un "futuro antiguo". Así se reflejará el lado más nostálgico del movimiento, su faceta más onírica y creativa. Por lo tanto, debemos abordar el presente estudio desde dos ámbitos conceptuales diferentes: de un lado, la postura prospectiva y de otro, la retrospectiva. Si los artistas y escritores steampunk miran hacia atrás para seguir hacia delante, la sociedad victoriana y algunos movimientos artísticos posteriores, desde la fascinación tecnocientífica, idearon un futuro partiendo de sus propias cotas contextuales. Estas iconografías victorianas y de movimientos posteriores, que imaginaron

\footnotetext{
${ }^{11}$ Vandermeer/Chambers, 2011: 205.

12 Ídem: 132-158.
} 
un futuro idealizado o paleofuturo ${ }^{13}$, servirán también de referentes a los artistas steampunk para elaborar sus producciones artísticas. Por este motivo se hace necesario hablar de una poética del tiempo, ya que para interpretar completamente una producción steampunk es necesario enmarcarla en esa combinación de anticipaciones y retrospecciones que originarán un producto totalmente ecléctico y poseedor de múltiples discursos.

Cuando nos referimos a paleofuturo debemos remitirnos a aquellas producciones artísticas llevadas a cabo entre finales del s. XIX y comienzos del XX que anticipaban un futuro que prometían un año 2000 lleno de semáforos y estaciones aéreas. Así, se puede apreciar en la (Fig.1). Dicha serie está compuesta por un conjunto de tarjetas de imágenes publicitarias realizadas en 1897-98 por la Fábrica de chocolate Gebr Stollwerck. Unas imágenes que serían comercializadas en el interior de los paquetes de las chocolatinas Stollwerck, facilitando la creación de un imaginario colectivo basado en la especulación de un futuro hipotético, en el cual la tecnología habría avanzado hasta tal punto que la vida terrestre y aérea quedarían totalmente unidas.

Este mismo procedimiento sucederá en Francia con la serie de estampas En l'an 2000 (1899-1910) de Jean Marc Côté. La muestra está compuesta por una serie de imágenes que ilustran los avances científicos franceses en el año 2000, pero imaginados desde el año 1899. $\mathrm{Al}$ menos 87 de ellas fueron concebidas por artistas como Jean-Marc Côté, impresas en los años 1900, 1901 y 1910 para decorar el interior de las cajas de cigarros y comercializarlas como cartas postales, aunque nunca fueron distribuidas. Debido a las dificultades financieras de la empresa que producía dichas postales, sólo se consiguieron publicar dos lotes: el primero, adquirido por el escritor Isaac Asimov que las expuso en la obra Futuredays: $A$ Nineteenth Century Vision of the Year 2000 (1986); el segundo, fue proyectado para la Exposición Universal de 1900 de Paris.

No menos importante sería la figura de Albert Robida, quien será uno de los mejores exponentes de la imaginería anticipativa. En sus obras Le Vingtième Siècle (1883) o La Guerre au vingtième siècle (1887) prevé muchos de los elementos de la vida cotidiana actuales, aunque un tanto idealizados. Incluso anticipa una guerra en la que se emplea gas asfixiante o misiles robotizados. Este espíritu creativo podemos encontrarlo en ilustraciones como Fig.2 Maison tournante aérienne para su libro Le Vingtième Siècle. En la Ilustración ya se reflejaban los primeros inventos que marcarán el s. XX, como el ascensor, pero concebido como un montacargas por el que una mujer asciende a base de un mecanismo de polea. Otro hombre, situado bajo la plataforma en la que se alza la casa superior aérea, es capaz mediante una serie de engranajes hacer girar la orientación de la casa.

El culmen de la fascinación tecnocientífica tendrá lugar una vez todos los modelos utópicos hayan conseguido materializarse. Este momento llegará con la aparición de los modelos de arquitectura Googie. Las promesas imposibles reflejadas en los modelos de ciudades del movimiento futurista y postales paleofuturistas se llevarán a cabo en un contexto donde el inconsciente colectivo estará fascinado por todos los adelantos que conlleva una Era espacial.

Por lo tanto, el Googie, Populuxe o Doo-Woop, surge en el seno de una sociedad de incipiente capitalismo. El empleo masivo del automóvil a finales de 1940, unido a la influencia de la Era espacial y Era atómica en el seno de la Guerra Fría, produce los primeros viajes espaciales, las investigaciones tecnologías para la exploración del espacio y las experimentaciones con la energía nuclear, originando en California este movimiento que estará vigente hasta mediados de la década de 1960. Un nombre que adopta hacia 1949, cuando el arquitecto John Lautner, discípulo de Frank Lloyd Wright, diseñó en Los Ángeles

13 Término creado por el académico Matt Noval que trabaja en la web Paleofuture del Smithsonian Institute. Para una mayor información véase: Roselló, Elisabet (2013): "Nostalgia, Retrofuturismos y Futuros imaginados". En https://es.scribd.com/doc/197257294/Recopilacion-2013-Una-Historiadora-en-el-futuroNostalgia-Retrofuturismos-y-Futuros-Imaginados [14/05/2016]. 


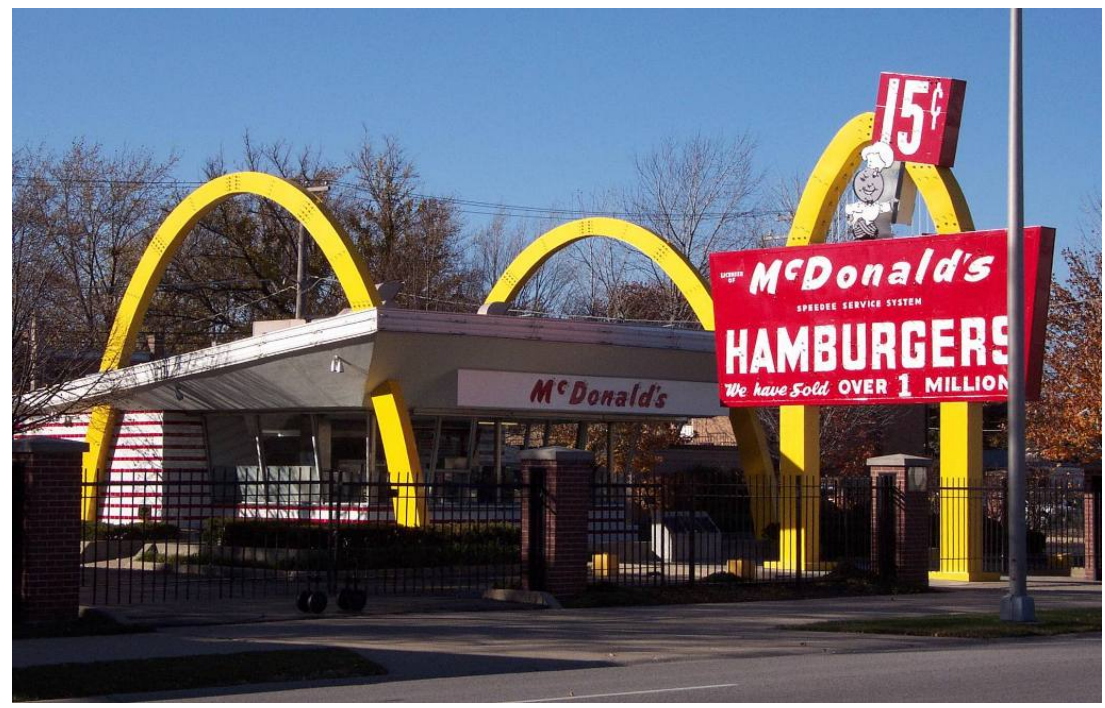

Fig. 3. Restaurante McDonald's de 1955, situado en Des Plaines (Illinois)

la cafetería con el nombre Googie's, situada en la esquina de Sunset Boulevard y Crescent Heights ${ }^{14}$. Este estilo no estará destinado al servicio de las grandes élites, sino al alcance de todos, por ello se empleó en cafeterías, moteles, restaurantes de carretera, gasolineras, estaciones de lavado o sedes bancarias. Además, es necesario tener en cuenta que el lema del movimiento Googie era "la forma sigue a la función", entroncando directamente con la influencia de Frank Lloyd Wright y con características de otros movimientos como el Pop Art. De hecho, en estos casos, la función y el edificio se unen para ser un elemento publicitario, conjugándose de esta manera el arte y la comunicación. Así, con el movimiento Googie se introdujo un espíritu innovador en la vida cotidiana que, desde el punto de vista de masas, ayudó a insertar los primeros spots publicitarios de gran formato unidos a la iluminación heredada de la vía aerodinámica del Art Déco. La invención del automóvil contribuyó a una renovación en la cartelería para poder destacar y promocionar los bienes de consumo, pasando a estar compuesta de colores llamativos, grandes formatos, luces de neón, etc. Así podemos apreciarlo en la (Fig.3) Restaurante McDonald's de 1955, situado en Des Plaines (Illinois). Nos hallamos ante una arquitectura muy dinámica que juega con el contraste de curvas y líneas rectas, poseyendo un tejado en saledizo muy volado dando la sensación de una verdadera estación espacial.

Esta estética marcaba una nueva era, el futuro de una tecnología simpática, benevolente y cercana $^{15}$. Su rápido éxito se debió a la fascinación que ejercía también el Space Opera que, junto con la revista Amażing Stories aparecida en 1926, continuarán con el progreso del futurismo, pero esta vez focalizado desde la óptica de la ciencia ficción. Esta dinámica fue aprovechada por las producciones cinematográficas hollywoodienses para insertar los preceptos básicos de la cultura americana, el individuo y el cuestionamiento de la libertad ${ }^{16}$ que, más tarde, serán retomados por películas como Star Wars VI: Una nueva esperanz̧a de George Lucas. Este y otros directores como Steven Spielberg pertenecerán a la generación

\footnotetext{
14 Demolida en 1980.

${ }^{15}$ Novak, Matt (2012): “Googie: Architecture of the Space Age: The futurist design movement that divided critics and swept the nation with space age coffee shops". En: http://www.smithsonianmag.com/history/googie-architecture-of-the-space-age-122837470/?no-ist $(03 / 11 / 16)$

16 Ante la consciencia de los diversos regímenes dictatoriales que se estaban llevando a cabo en otros países.
} 
"Happy Days"”7 que, retomando el Space Opera, introducirán de nuevo la visión futura esperanzadora, el optimismo, los valores de una sociedad valiente y honrada, la eterna lucha entre bien y mal o la democracia contra la tiranía, entre otros principios ${ }^{18}$. Sea como fuere, se trata de ejemplos ilustrativos de cómo el interés por recrear unos escenarios y unas maquinarias avanzadas contribuyeron a promover la sensación de vivir en un futuro mucho más esperanzador en el que estuvieran superados los conflictos bélicos o crisis económicas, al tiempo que originaron una serie de fascinaciones en la sociedad, impulsando y legitimando un modelo de ciudad avanzada cuyos pilares fundamentales residían en el avance tecnocientífico y en el consumo masivo.

Sin embargo, tras la ansiada llegada a la Luna en 1969 todo pasó a trivializarse y la fascinación espacial empezó a decrecer de forma abrupta. El desencanto aumentará con la consciencia del impacto que generaban los productos plásticos y la energía nuclear, surgiendo nuevas inquietudes como las ecologistas ${ }^{19}$. Además, el uso de drogas psicodélicas, aparte de alentar la ruptura de las fronteras, la empatía con los demás y la unidad entre las personas y naciones, proporcionó un tiempo en el que la población fue cada vez más consciente de los acontecimientos políticos, y con ello, empezaron a ser cuestionados los criterios autoridad establecidos. Entonces, ni los viajes a otros planetas diferentes a los nuestros, ni el uso de naves espaciales evitaron que apareciera el espíritu de decepción tecnocientífica.

En este sentido, la decepción tecnocientífica no surge de forma repentina a finales del siglo XX, sino que venía fraguándose desde mediados de dicha centuria, en el seno de EEUU, para más tarde extenderse al ámbito europeo ${ }^{20}$. Esta decepción se manifestará en los conceptos de contracultura ${ }^{21}$. Por tanto, encontraremos diferentes propuestas estéticas alternativas que surgen ante unos valores socialmente aceptados y que se ven reforzados por la presión de los mass media. Además, a finales de los años cincuenta y hasta los ochenta, irán surgiendo contraculturas que apostarán por diferentes posiciones estéticas evidenciando las diversas posturas en contra de los valores establecidos socialmente. Entre ellas, podemos mencionar los beats, beatniks, hípsters, hippies, mods o punkies, los cuales se manifestarán

17 Grupo de jóvenes autores que crearon sus producciones partiendo de la cultura de masas de los años 1940, 1950 y 1960. Etapas caracterizadas por la aparición de diversas tendencias como el Googie que anteriormente mencionábamos, el Space Opera, la aparición de la revista Amazing Stories y, sobre todo, la reaparición de las historias pulp o los serials de Flash Gordon (serie que constaba de catorce o quince capítulos de veinte minutos, que se difundían en el cine acompañados de la película).

${ }^{18}$ Colson, 2012: 19-26.

${ }^{19}$ Novak, Matt (2012): “Googie: Architecture of the Space Age: The futurist design movement that divided critics and swept the nation with space age coffee shops". En: http://www.smithsonianmag.com/history/googie-architecture-of-the-space-age-122837470/?no-ist $(03 / 11 / 16)$

${ }^{20}$ EEUU se convertirá en referente artístico e ideológico desde los años 40, en que París le transfiere la capitalidad mundial del arte tras el fin de la Segunda Guerra Mundial. Así se producirán diversos procesos de comunicación cultural en los cuales la cultura dominante americana transfiere sus ideologías (lenguaje, creencias, tecnología, etc.) al resto de los miembros con el consecuente cambio cultural original de uno o de ambos grupos. En ocasiones, esta dialéctica puede llevar a modificar la identidad étnica de los miembros produciéndose así deculturaciones, o bien recibir la influencia de la cultura preponderante desde la solidez étnica de los mismos.

${ }^{21}$ La contracultura es un movimiento de rebelión contra los valores patriarcales de la sociedad a favor de un modelo alternativo de cultura en el que predominen los valores ecológicos, sensorialistas y autárquicos. Surge en la década de los 60 con movimientos contraculturales que van desde los beatniks hasta los Hippies. En 1969, tras revoluciones como la del Mayo del 68, los hippies abandonarán su principal lugar de origen, San Francisco (California), para asentarse en comunas rurales regidas por una serie de principios como imaginación al poder, huida de todo concepto cerrado y canónico, vestimenta libre, música como elemento principal de comunicación al no poseer fronteras, importancia de la imagen como "lenguaje académico", decisiones basadas en el predominio de mesas redondas, superación de la monogamia y modelo de familia extensa, pacifismo antinuclear, superación del consumismo capitalista globalizado mediante el "hágalo usted mismo", una sociedad a la medida de nuestras necesidades, artesana y lúdica, etcétera. Realizarán así acciones políticas, desarrollarán filosofías coherentes, publicarán manifiestos y crearán "instituciones alternativas" (prensa underground, comunas, etc.). 
por medio de ropa, cortes de pelo o estilos e iconos de música, es decir, adoptan gustos, elementos y conductas que les permitan crear símbolos con los que sentirse identificados.

El estilo de vida punk será muy frecuente en el steampunk en forma de intencionalidad crítica. El punk revela una serie de imaginarios basados en una generación encadenada a un presente sin expectativas y sin futuro, vistiendo ropa sucia y agujereada, melena petrificada en tensión vertical, correas, cazadoras estrechas, posturas rígidas o cuerpos esqueléticos ante la obesidad de un estilo de vida sedentario. Adoptan así una retórica canalla y un tanto descarada que ayuda a exaltar los valores de la anarquía, la rendición y el declive. El punk sirve, pues, como una forma de manifestar la alienación producida por un estilo de vida globalizada y capitalista que sume al individuo en una consentida condición de exilio absoluto. Se exalta la incomunicación, lo impasible como vía de comunicación y expresión. En general, buscan hacer sentir el efecto que se experimenta al ver un cristal roto, pues ya no significa nada, no tiene valor en sí, pero nos está mostrando una consecuencia fruto de una acción que nos intriga ${ }^{22}$. Esta corriente punk influirá en movimientos posteriores, pese a su sentido más pesimista, como se puede apreciar en el Manifiesto Punk (2002) de Greg Graffin ${ }^{23}$, en el que se apela a la singularidad del carácter humano, y a su capacidad de reflexión y crítica, como elementos esenciales para el bienestar, frente a las renovaciones ideológicas procedentes de los mass media que apuestan por un modelo de vida basado en el aletargamiento y la conformidad. Sólo mediante el espíritu crítico y el cuestionamiento de lo "naturalmente establecido", las personas podrán dialogar entre sí para conseguir el progreso colectivo $^{24}$. Así, a través de esta vertiente punk, asistimos al nacimiento del Cyberpunk ${ }^{25}$ en los años ochenta, y al surgimiento de los primeros atisbos del steampunk en el Burning Man Festival ${ }^{6}$.

El movimiento Cyberpunk surge en noviembre de 1983 en la revista Amazing Science Fiction Stories $^{27}$, tratándose de un relato homónimo de Bruce Bethke, quien creará y popularizará el término. El movimiento surgirá como una forma de rechazo hacia la tecnología, que había dejado de ser simplemente una herramienta o accesorio para convertirse en elemento esencial de nuestras vidas, a través de elementos como internet o las primeras manifestaciones de una Inteligencia Artificial que empezaban a generar dependencia. Entonces, los ordenadores se vuelven personales, modificables y se interconectan, generando una nueva comunicación entendida desde la realidad virtual. A medida que va creciendo el desarrollo tecnológico, los cyberpunks empiezan a desconfiar cada vez más de estas transformaciones, sobre todo, al darse cuenta de que nuestro poder como ciudadanos va disminuyendo a favor de grandes corporaciones creadoras de estas nuevas "herramientas de vida".

Los principales representantes y teóricos de esta corriente son William Gibson y Bruce Sterling $^{28}$. El primero, publicará la obra de referencia Neuromante (1984), mientras que el segundo, creará la antología de Mirrorshades (1986). Sin embargo, ya se había sembrado la

22 Hebdige, 2004: 69-99.

23 Vocalista del grupo Bad Religion,

24 Graffin, Greg (2002): “A punk manifestó”. En: http://www.allidoispunk.com/about/greg-graffin-apunk-manifesto/ $(03 / 11 / 2016)$

${ }_{25}$ Concepto formado por la unión de Cyber, (cibernético) con el elemento crítico del punk. Según la RAE el término de la Cibernética surge del francés, cybernétique, y éste del inglés, cybernetics, que a su vez proviene

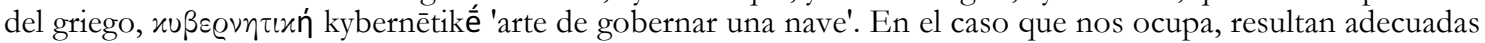
las acepciones cuarta y quinta: "Perteneciente o relativa a la realidad virtual. Viaje cibernético y ciencia que estudia las analogías entre los sistemas de control y comunicación de los seres vivos y los de las máquinas".

26 Acontecimiento que desarrollaremos más adelante.

27 En 1972 Ted White decidió cambiar el título de la revista Amazing Stories por el de Amazing Science Fiction Stories, alejándola ligeramente de las connotaciones pulp.

28 Sin olvidar a autores como Rudy Rucker, John Shirley o Lewis Shiner que junto a los otros dos, fueron conocidos como el grupo Mirror Shades ("Gafas de espejo"). Aunque el escritor manifieste su descontento con el encasillamiento y lo compare con la mitología de Procusto, lo cierto es que todos los autores cyberpunk comparten algunas características. 


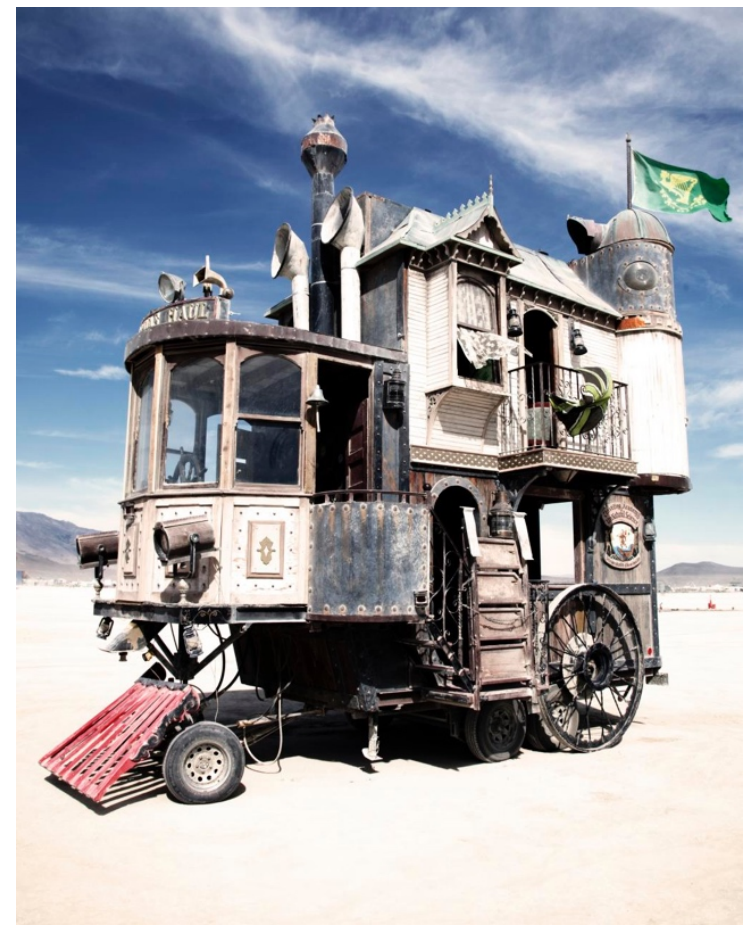

Fig. 4. The neverwas haul creada en 2006 por Shannon \& Katby O'Hare, Kimric Smythe

semilla crítica con Sueñan los androides con ovejas eléctricas (1968), una obra de Philip K. Dick, posteriormente adaptada libremente a la pantalla, titulándose Blade Runner (1982, Ridley Scott). Así, Dick tomará influencias de la novela negra, la música pop y el cine mezclados con el empleo en la ficción de drogas de diseño, implantes o prótesis electrónicas, para encuadrarse en un escenario distópico con tintes surrealistas, en algunas ocasiones, fruto de un futuro cercano que ya no nos resulta familiar. De esta manera, la gran tecnología es íntima, y no está fuera de nosotros, sino dentro, bajo nuestra piel y en el interior de nuestra mente. Ahora, abandonamos esas gigantescas maravillas de vapor o el Empire State Building, para dar paso a la tecnología de los ochentas, que se pega a la piel y responde al tacto mediante el ordenador, el teléfono móvil o el ipod entre otros dispositivos ${ }^{29}$. La necesidad de cambio del sistema se puede apreciar de forma clara en el Manifiesto Cyberpunk de Christian As. Kirtchev (1997), caracterizado por la exaltación de la mente electrónica, un exceso de información que cohíbe y una red en continua expansión, lo que acabará por sumir al mundo en el abismo de ceros y unos ${ }^{30}$.

Por otro lado, hemos de volver a mencionar el Burning Man Festival, un evento artístico anual que se celebra en el desierto Black Rock de Nevada (EEUU). Tuvo su creación en 1986 en San Francisco, donde un pequeño grupo de amigos se reunieron para quemar una efigie de madera en la celebración del solsticio de verano. Aunque este festival tendría dos antecedentes: por un lado, las connotaciones hippies del Wicked Man Festival y, por otro lado, un festival descrito como un espacio autónomo temporal dadaísta organizado por la Cacophonie Society ${ }^{31}$. De esta manera, el evento inaugural del Burning Man Festival tuvo tan buena acogida que se trasladó al desierto en 1990. Este festival ha sido descrito como una experiencia donde los ingredientes principales son la comunicación, el arte, la libre expresión y la autosuficiencia radical, cuyo punto central sigue siendo el mismo que en 1986, la quema de un hombre de madera colosal. Los asistentes al evento deben tener en cuenta que no solo

\footnotetext{
${ }^{29}$ Sterling, 1988: 9-26.

$30 \quad$ As.Kirtchev, http://project.cyberpunk.ru/idb/manifesto_es.html (04/11/2016)

31 Roselló, 2013a: 52.
} 
asisten al Burning Man, sino que también viven en él. Durante una semana se reúnen unas 52.000 personas y forman una auténtica capital en el desierto de Nevada, denominada Black Rock City ${ }^{32}$. Las personas que pasaran allí la semana, viven bajo la adhesión de un conjunto básico de normas para la seguridad pública, aunque se les permite adoptar sus propias decisiones acerca de cómo vivir sus vidas, es decir, los límites y las expectativas que rigen nuestra vida cotidiana no son aplicados allí. Durante el festival, islas de neón móviles deambulan por el desierto, autobuses enormes se transforman en bares de tres pisos que van de campamento en campamento, los coches parecen obras de arte, hay tiendas de campaña, enormes barcos del desierto construidos sobre los cimientos de autobuses viejos, máquinas de vapor o lámparas de gas. En este sentido, se aprecia cómo la imaginación se puede materializar para ser compartida con los demás. Este festival será muy importante, pues en él veremos una de las primeras manifestaciones steampunk: The neverwas haul (Fig. 4), creada en 2006 por Shannon \& Kathy O'Hare, Kimric Smythe y un gran equipo de voluntarios que contaban con un presupuesto muy bajo para su confección. Se trata de una casa de tres pisos con salón, balcón, comedor y otras dependencias, constituyendo una realización física de escala épica de la imaginación victoriana ${ }^{33}$. En cuanto a la concepción formal de la casa podemos apreciar una clara analogía con la Fig. 2 Maison tornante aérienne de Robida, especialmente, en el empleo de materiales como el metal y modelos arquitectónicos basados en vanos coronados con frontón, empleo de chimeneas o el uso de techado a dos vertientes.

Pese a que el steampunk nació como un movimiento contracultural, actualmente, podemos encontrarlo también en el sector mainstream. El movimiento, desde su nacimiento, está caracterizado por un fuerte eclecticismo, fruto de las diversas reacciones que se han producido en las sociedades antecesoras contra lo "naturalmente establecido", por lo que tratarán de revindicar la creatividad concediéndole al mundo que nos rodea una mirada nueva, guardando un ojo dirigido al pasado, mientras el otro mirará al futuro ${ }^{34}$. Así se pudo apreciar en la Primera convención de Steampunk celebrada en California en el año 2008 y así lo describe Jake von Slatt" : "Algunas personas iban completamente vestidas con trajes correspondientes a la época Victoriana, pero muchos más vestían de una manera ecléctica, combinando la anterior moda con el punk y el gótico entre elementos habituales de aventurero pulp o de serie B., ${ }^{36}$.

Esto evidencia una realidad en la habría que hacer distinciones dentro del movimiento ya que, desde el punto de vista histórico, los creadores más puristas se centrarán exclusivamente en la recreación de la época del vapor, mientras que otros "no les temblará el pulso" al realizar producciones completamente eclécticas, mezclando steampunk y dieselpunk, clockpunk con gótico, o incluso aportan influencias de la postal paleofuturista, anteriormente citadas, obteniendo así un resultado ecléctico que gira en torno a la literatura, el arte, la ciencia del pasado y la tecnología moderna. Por esta misma razón, el steampunk se enmarca dentro de la ciencia ficción y, particularmente, del retrofuturismo.

No obstante, a pesar de la importancia de la Convención Steampunk, el movimiento logró consolidarse y difundirse gracias al artículo de Ruth La Ferla, Steampunk Moves Between 2 worlds ${ }^{37}$, publicado en el New York Times, el 8 de mayo de 2008. En él, se desgranan las características del movimiento y su fascinación por la época Victoriana, a lo que se irán

32 El Desierto Black Rock de Nevada es un lago seco o, como se llama en el oeste Estados Unidos y México, una playa, cuya superficie desolada no está compuesta por arena, sino por un polvo fino alcalino fruto de la desecación del lago.

${ }^{33}$ Carrott/Johnson, 2013: 38-46.

${ }^{34}$ Boskovich/Vandermeer, 2016: 12.

35 Fundador de la Factoría Steampunk y gran exponente del movimiento.

36 Vandermeer/Chambers, 2013: 8.

37 Definiendo el steampunk como una subcultura que es la expresión estética de un mundo de fantasía, viajando en el tiempo, abarcando música, cine, diseño y moda, manifestaciones todas ellas inspiradas en la edad de los dirigibles y locomotoras de vapor, del casco de buceo de latón y los protosubmarinos. 
sumando otros componentes nuevos relacionados con el acercamiento del movimiento a su vertiente más punk. Gracias a éste, al Do It Yourself o el Do It With Others, y a la apuesta por el Arts and $\mathrm{Crafts}^{38}$, la obra adoptará su actitud más extraña, como si fuera fruto de un invento del científico demente del siglo XIX. Así se pone de manifiesto cómo no satisfacen los diseños y productos de masas hechos en plástico moldeado por inyección. Los artistas steampunk elaboran un nuevo estándar, mediante la adopción de materiales tradicionales del siglo XIX y su aplicación en la tecnología del siglo XXI. Alcanzando el pasado y el futuro, combinándolos en diseños que, en algunas ocasiones, no son únicamente agradables a la vista, sino que también son funcionales, prefiriéndose el objeto hecho a mano. El steampunk tampoco se considerará un gusto exclusivamente masculino, sus seguidores y creadores se dividen por igual entre hombres y mujeres, jóvenes y adultos, que pertenecen todas partes del mundo ${ }^{39}$.

Uno de los creadores más destacados del movimiento es Art Donovan, quien realizó la exposición de este movimiento más reconocida hasta la fecha, llamada Steampunk y celebrada en el Museo de Historia de la Ciencia de Oxford en $2010^{40}$. Donovan es muy conocido por sus enfoques elegantes y originales, y se ha convertido en un paradigma del movimiento gracias a su experiencia en diseño e ilustración, concibiendo, en algunas ocasiones, hasta juguetes futuristas. Sus proyectos están influenciados, no sólo por el estilo industrial, sino también por el art decó, lo retro o la vertiente histórica. Así, concibe el estilo industrial ${ }^{41}$ como una versión simplificada y realista del steampunk. Además, apostará por el crisol de culturas en obras como Shiva Mandala de 2009, representando el ciclo de la vida compuesto por cinco tipos distintos de piezas, con un astrolabio en el centro -que es copia de uno persa del siglo XIII- y a su alrededor cuatro planetas ${ }^{42}$.

Las composiciones de Donovan destacarán por el contraste de texturas, el uso de materiales naturales, el interés por captar la tercera dimensión y por su grandilocuencia. Esta última característica será un elemento esencial, a través del cual, el steampunk concibe el mundo que le rodea, creando una tensión melodramática en la que el efectismo, la teatralidad y el enigma juegan un rol primordial. Ejemplos paradigmáticos serán las lámparas inventadas por este artista, concebidas con un gran sentido teatral como podemos apreciar en Ravi Palace. Todas esas características hacen que el steampunk, al ser aplicado en los hogares como elemento de decoración de interiores, deba ser cuidadosamente medido. Un exceso de

${ }^{38} \mathrm{El}$ movimiento Arts and Crafts surgió en la segunda mitad del siglo XIX con el cuestionamiento de los productos industriales y el retorno a la producción artesanal. Esta reivindicación que se originó en Inglaterra, tuvo como principales exponentes a John Ruskin y William Morris. Ambos rechazaban la posibilidad de que los productos industriales pudieran tener valor estético y se imponían a la esclavitud de las máquinas en favor de la actividad artesanal, aunque Morris reconociera ciertas cualidades estéticas, pero como consecuencia de cualidades artesanales y no de la máquina. Partiendo de diferentes premisas, el Arts and Crafts vuelve a formar parte de nuestra sociedad desde la perspectiva del "Hazlo tú mismo", la autosuficiencia, el empoderamiento personal y la responsabilización sobre los objetos. Así, mediante el Craftivismo propugnado por Betsy Greer se busca conocer los bienes tecnológicos en profundidad, saber cómo funcionan y si se estropean volver a arreglarlos, así como saber elaborar una crema de verduras (slow food) sin recurrir a los precocinados (fast food), también la manera de fabricar tu propia ropa. Así, se proclamará el retorno a las artesanías y labores tradicionales desde la igualdad de géneros.

39 Donovan, 2013: 12-38.

${ }^{40}$ Las obras que se expusieron no sólo contaron con el elogio de la crítica y la atención de la prensa, sino que, según el recuento final, fue la exposición más vista desde que abriera el museo en 1683.

${ }^{41}$ Este estilo se popularizó desde hace 40 años. Hacia finales de los años sesenta revistas especializadas como United House W recking proponían todo tipo de opciones de reliquias industriales, agrícolas o naúticas para decorar y amueblar los espacios. El estilo industrial nace así con la moda de los lofts, espacios para vivir habilitados en edificios que anteriormente fueron fábricas, oficinas, etc., convirtiendo por tanto los lugares de trabajo en viviendas, partiendo de las estructuras que conformaban su uso original. Predominarán así las superficies rugosas, el ladrillo visto, los revestimientos de cemento y hormigón. Todos los materiales se dejarán en bruto, con tubos de aire acondicionado, tuberías y otros elementos estructurales a la vista. El cristal, las maderas naturales, el hierro y acero se convertirán en los materiales preponderantes en este tipo de decoraciones

${ }^{42}$ Vandermeer/Chambers, 2013: 121. 
producciones provocaría en los visitantes cierto desconcierto, intimidación y sobresaturación ante unos diseños que apuestan por una estética casi onírica y ecléctica procedente de la combinación de elementos de diferentes épocas. Un apartamento no puede ser solamente un parque de atracciones, por ello la distribución de la decoración dependerá, en muchas de las ocasiones, del tiempo que pase la persona dentro del hogar. Por norma general, la decoración será empleada con mesura, ya que está constatado como el espectador puede captar mejor la esencia cautivadora de este tipo de producciones sin una sobresaturación ${ }^{43}$.

Un planteamiento diferente es el desarrollado por el artista Hyeronimus Isambard, mejor conocido como Jake Von Slatt, que destaca dentro del movimiento por su vertiente maker ${ }^{44}$. En este sentido, se describe como hacker de hardware, manitas y propietario de la página web de Steampunk Workshop. Sus fuentes de inspiración serán el movimiento Arts and Crafts británico y el aspecto de "Tomorrowland" de Disney. Jake von Slatt ha realizado algunas de las creaciones más representativas en su taller Massachussetts siendo su arte una mezcla de la decoración y los elementos prácticos. Slatt trabaja así con piezas y máquinas que recoge de los lugares por donde pasa o que va encontrando, y los utiliza de una forma particular, ofreciendo su propia visión. Enfatizando en la vertiente más punk, es decir, lo rebelde y "marginal" de la obra, pero sin renunciar a una cuidada estética en la misma. De esta manera, su obra gira en torno al arte y la ciencia, conservando un don para reciclar desechos, por lo que su creatividad no sólo reside en un simple talento de manitas o carpintero, sino que es un artista que deja su impronta y personalidad en la producción, a través de un diseño muy estudiado. Como vemos, el reciclaje es vital dentro de su producción artística, confiriéndole una poética muy atractiva al hacer de lo viejo algo nuevo y estético ${ }^{45}$.

En su obra Cerebro Bassington, se puede apreciar estas cualidades, se encuentra realizado a base de materiales encontrados, este "cerebro mecánico" se posiciona contra el consumismo masivo que propicia la economía capitalista y la obsolescencia, para favorecer el reciclaje y la segunda oportunidad de los materiales. Aunque irá más allá, con piezas como ésta el artista pretende mostrar al espectador que hay una funcionalidad tras un estudiado gran diseño, sin embargo, en sus esculturas la única pretensión reside en hacer volar la imaginación del que la percibe, otorgando a los espectadores la posibilidad de ser nuevos creadores. En sus propias palabras, ante su obra nos encontramos "descubriendo historias secretas y tecnologías obsoletas que conducirán hacia mundos alternativos y fascinantes" ${ }^{46}$. Otra producción interesante es su Ordenador personal multifuncional victoriano con modificaciones, un ordenador de estilo victoriano con un monitor de bronce adornado con elementos vegetales dorados, para cuya realización descompuso el equipo en pedazos y lo reconstruyó como lo hubiera imaginado un inventor de estilo victoriano, teniendo en cuenta las partes e informado de su función ${ }^{47}$.

\footnotetext{
43 Boskovich/Vandermeer, 2016: 96-99.

${ }^{44}$ La tendencia Maker surge con la presentación de la impresora 3D en EEUU de carácter doméstico y cada vez más asequible. El manifiesto Maker deja en evidencia que estamos viviendo una Tercera Revolución Industrial en la que debemos tener en cuenta una serie de valores que giran en torno a la capacidad creativa como actividad intrínseca en el ser humano, única vía para sentirnos plenos. Por ello, compartir lo que hemos creado es esencial, hay que difundir el conocimiento para aprender en colectividad. Regalar es algo desinteresado y satisfactorio que debe propiciarse, de esta forma, otorgamos pequeñas partes de nosotros mismos. El hecho de convertirse en maestro artesano o constructor no significa parar de aprender. Se debe invertir en herramientas que resulten útiles para materializar tu idea, no en un bien de consumo masivo. Es necesario participar no sólo creando productos, sino realizando seminarios, fiestas, eventos o exposiciones. Así el movimiento Maker estará influenciado por el activismo del Do It Yourself de los hippies y punks americanos, la cultura autodidacta y emprendedora, y la escena cibercultural/cyberpunk de California que desemboca en hackear la tecnología, apoderarse de técnicas para crear los conceptos que tenemos en la cabeza, customizar los bienes de consumo, dar mejor vida a los objetos, repararlos, reciclarlos y, en algunas ocasiones, convertirlos en arte estimulando un modelo de vida basado en la cultura libre.

45 Ibidem: 28

46 Ibidem: 158-160.

${ }^{47}$ Roland, 2014: 106.
} 


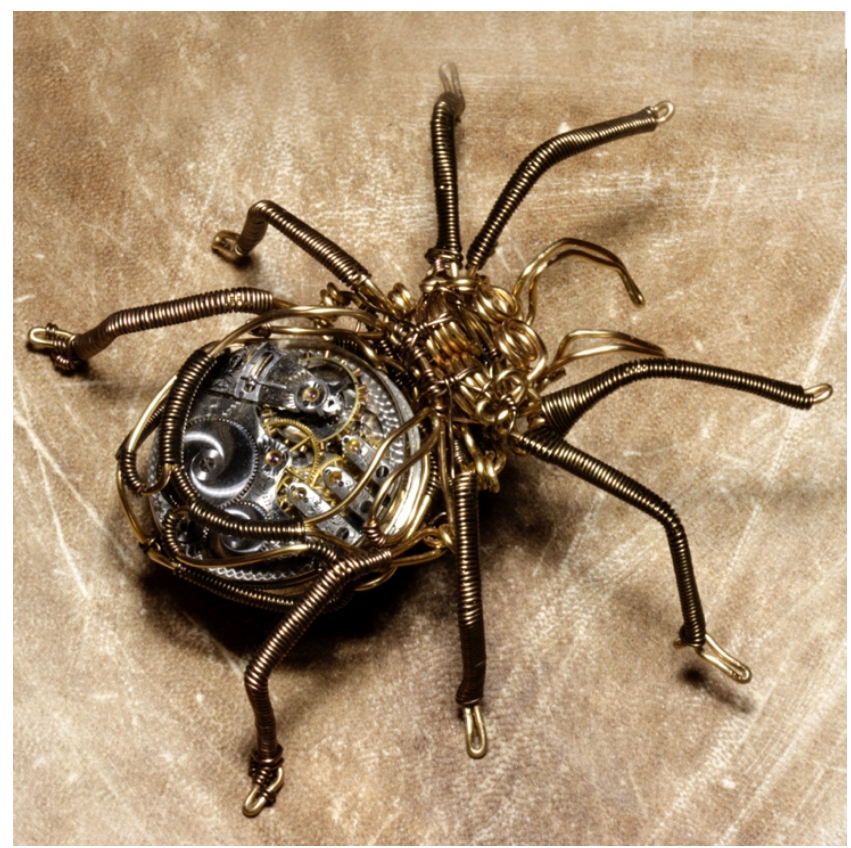

Fig. 5. Escultura de araña. Daniel Proulx.

Además, Jake von Slatt será el autor del Manifiesto Steampunk (Apéndice 1), en el que ya se pueden apreciar algunas características del movimiento como el desencanto por las promesas del futuro ideal que se hicieron durante el final del siglo $\mathrm{XX}^{48}$, situándonos ante una realidad basada en la alta tecnología y laboratorios I+D, reclamando el "Házlo tú mismo" para que el producto sea duradero, frente a un modelo de vida que en un futuro será desafiante debido al desgaste del petróleo y el consumismo capitalista masivo del cual reniegan por completo ${ }^{49}$.

Todo cuanto hemos señalado nos lleva a plantearnos hasta qué punto el mirar hacia atrás, hacia lo retro, es un acto original, reinterpretativo o copia. En este sentido, los estudios de Mackinney-Valentin son muy clarificadores al investigar la influencia retro en nuestra actualidad, distinguiendo tres tipos de producciones retro: el revival material -cuando se manifiesta una reproducción total del bien o parcial-, el revival inmaterial -cuando se crea un bien partiendo de la reinterpretación o influencias de movimientos u otras producciones- y el revival literal -cuando creamos un bien partiendo de la copia directa atendiendo a lo inmaterial ${ }^{50}$-. Esta teoría cobra aún mayor fuerza, reflejándose en la tendencia al arqueomodernismo en la que los artistas crean sus producciones artísticas apoyándose en acontecimientos, personajes, dispositivos o producciones técnicas que realmente existieron. Los artistas recuperarán así objetos del pasado, modificando sólo algunos elementos y permitiendo nuestra retrospección hacia el pasado donde fue usado ${ }^{51}$.

Por ejemplo, el grupo musical finlandés Steampunk Pepe Deluxe recuperará del pasado un instrumento concreto como es el theremín, uno de los primeros instrumentos musicales de carácter electrófono surgido en el siglo XX, cuya única diferencia con los originales es que la función que lleve a cabo se realizará en un contexto totalmente diferente al de origen. Otro instrumento de invención propia es una máquina que ofrece una percusión neumática. Además, como suele ser frecuente en los espectáculos steampunk, formarán parte de su escenificación textos poéticos, proyecciones de imágenes o ilustraciones retro, e incluso collages caleidoscópicos, mezclando así realidad e imaginación y consiguiendo una atmosfera

48 Promesas como sirvientes robóticos, coches que se conducirían solos, vacaciones en hoteles orbitando en el espacio o un futuro comprometido con la ecología.

${ }^{49}$ VanderMeer/Chambers, 2013: 216-218.

${ }^{50}$ Mackinney-Valentin, 2010: 68-69.

51 Sanz et Alii, 2012: 7. 


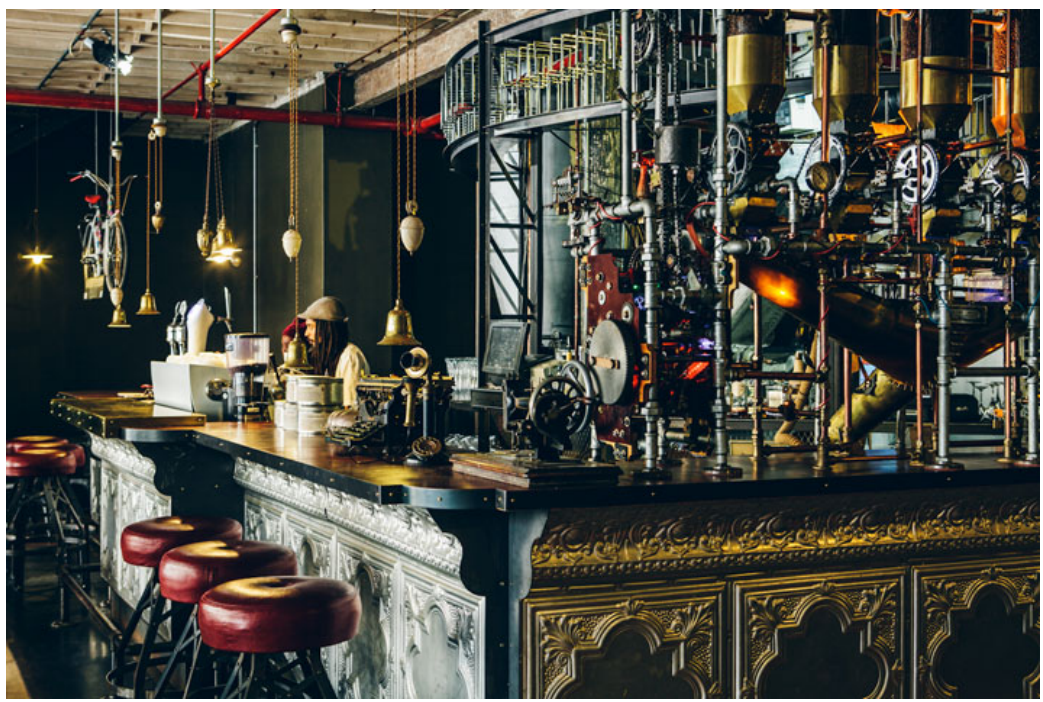

Fig. 6. Ejemplo de mainstream, Detalle interior de la Cafetería Truth, África del Sur.

multi-sensorial con la combinación de diversos recursos artísticos. En cuanto a la influencia estética, los espectáculos steampunk heredan las formas artísticas más variadas de finales del siglo XIX y del XX, como las procedentes del burlesque, el vodevil, el teatro de variedades, el circo o incluso la danza del vientre ${ }^{52}$.

En cualquier caso, independientemente del tipo de revival que lleve a cabo el artista, debemos enfatizar en su capacidad crítica ante de la sociedad en la que se produce, cualidad que lo hace único. Por ejemplo, el artista Daniel Proulx en su Escultura de araña (Fig.5) pondrá en tela de juicio hasta qué punto ha llegado la mecanización a nuestras vidas, lo que nos lleva a pensar en la idea de cómo la tecnología invade por completo la naturaleza. Así podemos apreciar un impulso exacerbado por humanizar y personalizar la tecnología generando un interés por estudiar la fusión entre lo orgánico y lo mecánico. Aunque quizás perspectiva más radical nos conduce hasta la serie de esculturas de Mike Libby con obras como Dynastidae Eupatorus Gracilicornis (2009) en la cual, gracias a pinzas, limas, papel de lija o alicates se aprecia el interés del artista por capturar insectos y modificarlos haciendo una mezcla entre lo orgánico y lo mecánico, pero no con un fin práctico y funcional, sino buscando un fin estético. Basándose en historias de la ciencia ficción, donde se presentan a muchos seres alienígenas en forma de insectos que vienen a invadir La Tierra. Como podemos comprobar, en este ejemplo, se reforzaría ese aspecto, por un lado, la mezcla de ciencia ficción con los experimentos científicos y, por otro, la faceta de científico loco que podemos encontrar en el steampunk ${ }^{53}$.

Otro aspecto llamativo del steampunk es su interculturalidad, producida por un mundo globalizado gracias a la Revolución Digital y al avance de internet que permiten cada día que millones de personas entren en contacto instantáneo entre sí. La introducción del personal computer a precios asequibles originó un cambio de vida que conllevó la aparición de teléfonos móviles o mails, y en poco tiempo se trasladó también al ámbito de las telecomunicaciones. Entonces, surgen las tecnologías de la información y la comunicación en la vida social, a través de redes sociales o las tecnologías de empoderamiento personal, así como en la vida laboral, mediante el trabajo on-line y la desaparición o modificación del ritmo cotidiano de

52 Bosckovich/VanderMeer, 2016: 192-195.

53 VandeMeer/Chambers, 2013: 109-116. 
los trabajos físicos. Así, las fronteras entre vida pública y privada, lo real y lo virtual, cuerpo y mente se difuminan y se vuelven territorios inciertos ${ }^{54}$.

Pese a todo, estas circunstancias también permitirán que estilos como el steampunk se expandan por el mundo, pudiéndose hablar de un fenómeno globalizado en el que artistas como James $\mathrm{Ng}$, nacido en Hong Kong, reinterpretan el movimiento desde una perspectiva china y su historia. Este artista se preguntará qué hubiera ocurrido si China hubiera sido la primera ciudad en modernizarse y en vivir la Revolución Industria ${ }^{55}$, lo que puede apreciarse en producciones como Inmortal Empress inspirado en la emperatriz viuda Cixí de la dinastía Qing, en la que podemos ver cómo en el trono aparecen elementos orientalizantes a través de recursos como la epigrafía y los dragones chinos mezclados con manivelas y chimeneas procedentes de la estética industrial. Además, en su obra Imperial Airship se puede evidenciar como el inventor está al servicio de la familia imperial, creando un barco volador a modo de dragón chino que parece reproducir a nivel estructural la forma de un dirigible propulsado por aspa.

Además, la globalización permitirá también que el steampunk deje de ser un arte crítico y alternativo al pasar por el filtro del mainstream ${ }^{56}$. Ello no quiere decir que pierda todo su interés, pues gracias a esto contamos con otras perspectivas diferentes sobre el movimiento. Buen ejemplo de este fenómeno son los diseños retrofuturistas del ámbito de la decoración de interiores, empleando el steampunk dentro del estilo industrial como sucede en la cafetería Truth, ubicada en África del Sur. La decoración realizada por el grupo de Haldane Martin mezcla lo retro y lo contemporáneo en una estética en bruto y elegante. El edificio, que data de finales del siglo XX, cuenta con dos plantas y el trabajo en él consistió en desvestir los muros para encontrar la piedra y el ladrillo de sus orígenes, así como en de equiparlo con teléfonos antiguos, máquinas de escribir y otros elementos del pasado, formando un escenario antiguo que se articula en torno a un viejo torrefactor, una mesa grande de ocho metros compuesta con pies de tubos industriales y recubierta de una placa de pino, y asientos que van desde tapizados en cuero hasta ser taburetes de bar ${ }^{57}$.

\section{Conclusiones: una estética atemporal en la sociedad de la continua incertidumbre}

La mejor respuesta para describir la situación actual, tanto desde el punto de vista artístico como social, vendría dada por los estudios de Bauman. En la mayoría de las ocasiones, inconscientemente, nos hallamos inmersos en una modernidad líquida. Cambiamos, mutamos continuamente, como las cifras de las acciones de bolsa. Lo persistente, sólido e inmutable se torna caduco. Vivimos en una continua adaptación ante los acontecimientos, no hay certezas, simplemente diferentes modos de actuar y roles por adquirir ante determinadas situaciones, de manera que estamos inmersos en una incesante performatividad. Así la identidad personal entrará en crisis al ser siempre cambiante, en consonancia con un mundo en el que predomina lo instantáneo, como lo demuestra la rapidez imperante de los medios de comunicación presente en aplicaciones como Skype o WhatsApp.

Por tanto, los roles que ya estaban consolidados antaño se vuelven ahora inestables en una sociedad en que la Revolución Digital y el mercado estructuran todo cuanto nos rodea. El modelo de familia nuclear queda afectado ante un individualismo masivo donde los vínculos entre los familiares son cada vez más débiles y se produce abandono a la primera dificultad que surja en su seno. El afecto se vuelve así desconcertante, la responsabilidad y el

${ }^{54}$ Roselló, 2013b: 19-29.

55 VandeMeer/Chambers, 2013: 215.

56 El término de origen inglés está compuesto por dos expresiones: "main" que significa "principal” y "stream" que expresa "corriente o flujo". Así servirá para referirse a las principales vías de creación apoyadas por el sistema capitalista de masas y con altas probabilidades de ser booms comerciales.

${ }^{57}$ Boskovich/VanderMeer, 2016: 100-106. 
compromiso para con los demás quedan sujetos a una perspectiva de beneficio, interesada, y no altruista. Satisface más la idealización, nuestro puro ego que percibimos a través de un perfil en la web, que el interés por conocer a una persona en un espacio tridimensional y físico. Estas percepciones aparecen ya en Tres ecologias (1996) de Félix Guattari, donde se puede distinguir cómo el planeta Tierra padece continuas transformaciones técnicocientíficas que conllevan fenómenos de desequilibrio ecológico y transforman radicalmente los modos de vida humanos individuales y colectivos, evolucionando hacia el declive.

La Revolución Digital lejos de crear bienestar y estimular el desarrollo en el sector laboral, acentúa la diferenciación entre los trabajadores, reservando un espacio extraño y marginal para los desempleados, relegados a quedar fuera del sistema. Las circunstancias tampoco serán estables para los trabajadores, ya que sus empleos serán cada vez más precarios estimulando la inseguridad ante su posible pérdida y, en multitud de ocasiones, el pluriempleo del minijob para poder hacer frente a todos los gastos del sistema.

La incertidumbre imperante y la ignorancia por no poder controlar nada, son también factores a tener en cuenta al instalar el miedo como costumbre en la sociedad. La defensa del ciudadano también entrará en crisis, el terrorismo ya no sólo es físico, sino que es virtual, reside en los foros, en las redes sociales, en las cuentas personales de email, estará en todas partes a solo un clic de ratón. Esta situación también se extrapolará a fenómenos negativos como el cyberbullying, la pornografía infantil o la publicidad cada vez más engañosa del mundo virtual, entre otros.

Ante un panorama tan globalizado la creatividad artística ya no conoce fronteras, lo que propicia los fenómenos de interculturalidad al estar los diferentes creadores en una continua dialéctica a través de Internet. Así, ven, producen, reproducen, interpretan, reinterpretan, etc. La creación artística no está muerta, simplemente, al igual que la originalidad, se han transformado. La época de la reproductibilidad técnica ha quedado más que superada, ya no importa si una "obra de arte" posee o no posee aura, por el contrario, si el aura se ha enfriado pasando la obra a ser un objeto común. La teoría institucional del arte y su mercado lo han abarcado todo, favoreciendo un arte de mainstream y el surgimiento de otras vías de creación "marginadas".

En medio de toda esta situación se hallan los artistas retrofuturistas (steampunk, dieselpunk o clockpunk,), junto con otros movimientos como el Maker o el nuevo Arts and Crafts. Ambos reivindican un arte más personal y no tan mediatizado, un arte en los que inviertan algo de ellos mismos y no estén sujetos al diseño reproducible masivamente. Así, se generarán micro-movimientos, con similitudes y diferencias que podrían conducirnos al interés de devolver los movimientos de vanguardias al panorama artístico para convivir junto al mainstream.

Por ello, estos micro-movimientos se proponen superar el postmodernismo para abordar un posthumanismo donde los cambios radicales, al son de las revoluciones tecnológicas, sean acometidos desde el punto de vista artístico individual, pero centrándose también en todos los elementos que los unen al producirse una dialéctica artística continúa. En consecuencia, el apropiacionismo y revisión de un bien artístico quedará más que superada. Las inclinaciones hacia el reciclaje y un arte sostenible harán frente al consumismo masivo, concienciando indirecta o directamente a las masas del declive al que están sometidas.

Así, mediante la reflexión y revisión de corrientes artísticas y la influencia de acontecimientos pasados, crearán un arte rico, crítico y atemporal. Al mismo tiempo, esta originalidad les ayudará a cuestionarse diversos aspectos de la vida e incluso a servir como fuente de inspiración para crear nuevos discursos artísticos.

Por tanto, ya no importará si se es fabricante o artista, puesto que no hay frontera que los separe. Ambas vías de creación se unen para formar un arte comprometido y estético. Todos trabajando en conjunto crean un producto único y colectivo, por lo que el fabricante y el artista finalmente son uno. En consecuencia, el genio artístico como tal, aun cuando encontremos personalidades reconocidas, desaparecería en pro al trabajo en equipo y de pequeños movimientos de vanguardia. 
Todo ello no quiere decir que la vertiente mainstream del steampunk sea peyorativa, también cuenta con su lado vanguardista, es más, el steampunk está pasando por una crisis de originalidad al trivializar su lado más crítico, centrándose en la representación de los elementos más banales. Mientras que el rasgo característico y original se puede percibir a través de los diseñadores de moda, creando verdaderas obras únicas y singulares. Por lo tanto, la diferenciación peyorativa entre subcultura y cultura mainstream ya no es válida, pues ambas son perfectamente complementarias. Estudiar el steampunk y remontarnos al interés por la Revolución Industrial, nos ha permitido no sólo entender cómo surge el movimiento, sino también aprehender cómo la naturaleza y la tecnología en continua dialéctica han ido configurando nuestra forma de entender el mundo actual en clave tecnocientífica. Por otro lado, el auge que está experimentando la ciencia ficción y, en concreto, los retrofuturismos en los mass media, es muy significativo, pues el recurrir todo el tiempo a elementos pasados nos conduciría a pensar ¿Por qué no se anticipa el futuro?, ¿La sociedad líquida de incertidumbre y cambio no nos deja concebirlo? Puede que simplemente impere la perspectiva del no future.

Así, a través de la introducción de las nuevas tecnologías y sus consecuentes efectos, llegamos a una situación en la que la única forma posible de interpretar el arte sea en clave de cultura visual. Ya no hay diferenciación entre el mundo físico y el virtual, a causa de los avances tecnocientíficos, como bien podía apreciarse en las postales de paleofuturo, ya somos uno. Cada vez nos acercamos más a entender el mundo en cifras cambiantes de ceros y unos, y apoyados en la inteligencia artificial, elementos que posibilitan que nuestras fascinaciones y ambiciones sean perfectamente materializadas. Sin embargo, todo esto origina una serie de interrogantes: ¿Sabremos discernir lo legítimo de lo ilegítimo?, ¿llegaremos al punto de vivir en una ciudad virtual?, ¿`seguiremos permitiendo que el sistema haga diferenciaciones entre desechos humanos y trabajadores? y, por último, ¿debe el arte reivindicar todo esto? Sólo el tiempo lo dirá. 
Bibliografía

AA.VV., Steampunk cinema : un repaso a las 25 mejores películas steampunk de la historia. Barcelona: Tyrannosaurus Books. (2013)

Boskovich, D./VanderMeer, J.: Le Manuel Steampunk, Guide illustré, pratique, et excentrique pour la création des rêves rétrofuturistes. Paris : Bragelonne. (2016)

Brummett, B./Halverson, P.D.: Clockwork rhetoric : the language and style of steampunk. Jackson, Mississippi: University Press of Mississippi. (2014)

Carrot, J. H./Johnson, B. D.): Vintage Tomorrows: A historian and a futurist journey through steampunk into the future of technology. United States of America: 0'Reilly. (2013)

Colson, R. et Alii. : Retro-Futur! Demain s'est déjà produit. Lyon : Les moutons électriques. (2012)

Donovan, A.: The Art of Steampunk: Extraordinary and Ingenious Contraptions from the Leading Artists of the Steampunk Movement. East Petersburg: Fox Chapel (Revised Second Edition). (2013)

Guattari, F.: Las tres ecologías. Valencia: Pre-Textos. (1996)

Hebdige, D.: subcultura, el significado del estilo. Barcelona: Paidós.(2004)

Mackinney-Valentin, M.: "Old News? Understanding Retro Trends in 21st Century Fashion". En: Multi (Rochester), vol. 3, n¹, Rochester, (2010)pp. 67-84.

Palma, F. J. et Alii .: Steampunk: Antología Retrofuturista. Madrid: Fábulas de Albión. (2012)

Robida, A.: Le vingtième siècle. París: G.Decaux. (1883)

Roland, P.: Steampunk: Back to the Future with the New Victorians. Herts: Oldcastle Books. (2014)

Román Roselló, E.: Nostalgia, Retrofuturismos y Futuros imaginados. Barcelona: Edición electrónica. (2013a)

Roselló Román, E.: Crafts, Makers y III Revolución Industrial. Barcelona: Edición Electrónica. (2013b)

Sanz, J.F. et Alii: Futur Antérieur. Bressons : Le mot et le reste. (2012)

Sterling, B.: Mirrorshades: Una antología cyberpunk. Madrid: Siruela. (1988)

Vandermeer J./Chambers, S.J.: La biblia steampunk. Sevilla: Edge. (2013) 